\title{
SENTENTIAE NA ÉPICA LATINA
}

\author{
MARTin T. Dinter
}

King's College London/USP

\begin{abstract}
Resumo. Este artigo examina as sententiae, um expediente retórico bastante negligenciado da épica latina, em Virgílio e Lucano. Enquanto as sententiae de Virgílio são frequentemente citadas por autores posteriores, Lucano, em particular, ficou famoso na Antiguidade por suas sententiae altamente retóricas (Inst. Or. 10.1.90). Lucano concentra seus esforços no nível sintático a fim de criar frases únicas e memoráveis, as quais asseguram o Nachleben de seu épico - haja vista que são extraíveis de seus contextos originais e realocáveis em novos contextos. Ler Lucano como uma mina de versos singulares não é uma imposição moderna, mas, ao contrário, confirma que este estilo de leitura exibe a força de formulações enérgicas sobre temas-chave da épica lucaniana, tais como derrocada e fuga. As sententiae estabelecem as leis da épica e, simultaneamente, criam um discurso sobre valores que se estendem por toda a épica.
\end{abstract}

Palavras-chave. Sententiae, épica latina, Virgílio, Lucano, fuga, apocalipse.

EM SUA INSTITUIÇÃo ORATÓRIA, QUINTILIANO NOS FORNECE UMA PERSPECTIVA retórica da literatura latina. Virgílio, o autor da Eneida, encabeça a lista de autores latinos os quais Quintiliano especialmente recomenda a leitura (Inst. Or. 10.1.85ss). De todos os autores gregos e latinos, Virgílio é posto somente atrás de Homero e muito à frente de outros poetas latinos. A alta estima na qual Quintiliano mantem Virgílio fica evidente pelo fato de haver mais referências na Instituição a Virgílio do que a qualquer outro autor, exceto Cícero. Com certeza, a recomendação de Quintiliano - a de ler Virgílio - reflete uma prática bem estabelecida em seu tempo.

O uso de Virgílio como manual nas escolas, sobretudo, garantiu-lhe sua influência duradoura. Ao contrário do que Quintiliano comenta sobre o poeta neroniano, Lucano, Virgílio - na opinião de Quintiliano - oferece mais poesia do que retórica (Inst. Or. 10.1.90). No entanto, o poeta da Eneida não é aclamado como sententiis clarissimus ("o mais distinto por suas sententiae"), um epíteto que Quintiliano confere a Lucano. Embora não seja usual reconhecer a Eneida como um épico retórico, traços do gosto pela retórica, próprio da época de Virgílio, podem ser encontrados. Virgílio oferece a seus leitores inúmeros discursos e sententiae. Na verdade, o fato de que há na 
Eneida algumas sententiae louváveis é confirmado quando Quintiliano usa dois versos virgilianos em sua exposição de sententiae (7.5.1 ss): usque adeone mori miserum est (Verg. A. 12.646) e tantae molis erat Romanam condere gentem (Verg. A. 1.33). Quintiliano, porém, nunca cita Lucano.

Neste artigo, irei discutir essa questão a fundo, examinando o que o rótulo "retórico" significa de fato. Distanciar-me-ei de discutir a épica retórica de um modo geral. Ao invés disso, perguntarei como a retórica quando fixada a pontos verbais detalhados funciona na composição da épica virgiliana. Farei isso observando um expediente retórico específico, as sententiae, que aparecem por toda a épica em muitas formas e tamanhos. Em seguida, examinarei como as sententiae de Virgílio servem como portadores de sua retórica e são indispensáveis para a criação do discurso épico. Depois, voltar-me-ei para as sententiae em Lucano.

Nas escolas de oradores da Roma Imperial "os poetas eram estudados não apenas como exemplos de técnicas retóricas, mas, sobretudo, como exemplos de epigramas (sententiae)".' Os epigramas na épica funcionavam como "capital cultural", selecionados com entusiasmo pelo leitor culto. ${ }^{2} \mathrm{~A}$ épica virgiliana é, portanto, uma mina de ouro de sententiae. Tal característica assegurou a Virgílio um pós-vida fragmentário, na medida em que permitiu o reuso de suas sententiae em textos distintos. ${ }^{3}$

Sententiae são tidas como pontos-alto de arte retórica e vistas como o legado mais duradouro do autor, além disso, são extraíveis e incorporáveis em novos textos literários. Uma vez que a pergunta correta a se fazer sobre as sententiae é "não se são verdadeiras em sentido absoluto, mas se são convincentes em seus próprios contextos particulares", as sententiae ajudam a construir uma base ética plausível para a apresentação da visão do autor. Haja vista que o autor supõe que seu leitor é alguém com quem são compartilhados pressupostos e valores, alguém - dentre os leitores - poderia se perguntar "Isso funciona assim mesmo?". ${ }^{4}$ As sententiae obrigam o leitor a registrar os eventos de um ponto de vista particular e, comumente, parcial. ${ }^{5}$ Ao retratar valores e crenças comuns, elas auxiliam o leitor a construir o universo do texto. Consequentemente, sententiae colocam seu usu-

Keith 2000, 17. Além disso, no início do treinamento retórico padrão havia exercícios "nas quais os estudantes trabalhavam uma anedota, que culminava em um ditado, elaboravam provérbios ou apophthegma e compunham uma fábula e uma narrativa simples" (Fantham 2004, 87). Sobre o pós-vida poético de versos singulares de Virgílio, chamados centos, cf. McGill 2005.

2 Cf. Keith 2000, 17.

3 Cf. Sanford 1934.

${ }^{4}$ Sinclair 1995, 35.

${ }^{5}$ Cf. Sinclair 1995, 6, para uma discussão sobre os padrões legalistas nas sententiae e sobre a questão de Tácito como um historiador nomotético. 
ário em uma posição de autoridade. Resumindo, o emprego das sententiae economiza em argumentação e faz com que nenhum leitor fique em dúvida quanto às premissas do texto.

Podemos atribuir significado às sententiae não apenas em seu contexto imediato, mas também as alinhando como uma cadeia de reflexões em série. ${ }^{6}$ Quando lidas dessa forma, elas sinalizam algumas das questões que estão em jogo na Eneida. Helen Morales analisou as sententiae em outro texto de larga escala, a novela Leucipe e Clitofon, de Aquiles Tácio. ${ }^{7}$ Ela segue a noção de Bennington de que "formulações sentenciais implicam um julgamento atrelado às normas sociais; elas transmitem uma herança cultural e são, inerentemente, conservadoras". ${ }^{8}$ Morales, então, propõe a questão: "Quais são os valores e normas da sociedade da novela e qual tipo de plausibilidade é relevante a Aquiles Tácio?"9 Tal abordagem se mostra bastante frutífera apenas se olharmos, como faz Morales, para posicionamentos genéricos e universais e descrições em um texto. No entanto - e isso será bastante relevante ao meu estudo - Bennington eleva estas estratégias um passo adiante quando diz que:

sententiousness becomes no longe so much a "type of sentence" as force in texts [...]. This force is not some irrational or metaphysical entity assumed to be at work in texts, but a force of law. If the "overt" forms of sententiousness lay down the law, the more concealed types [...] draw their force from a law laid down, or exploit that law surreptitiosly. ${ }^{10}$

Portanto, o que une a novela francesa do século xviII, Leucipe e Clitofon e a épica virgiliana, como também a de Lucano, - e também os fazem comparáveis do ponto de vista da presença das sententiae - é sua trajetória narrativa, o fato que eles criaram e dispuseram seus próprios universos com seus sistemas de valores. ${ }^{11}$ Ao observar somente as sententiae, nós estripamos a

${ }^{6}$ Rieks $(1978,367)$ identifica tópicos recorrentes na produção de Públio Siro, tais como vida e morte, mudança de fortuna, injustiça/justiça, sabedoria e ignorância, liberdade e escravidão. O último par conecta-se com a biografia de Públio, sua ascensão de escravo a homem livre. Fantham \& Duff $(1996,1276)$, no entanto, notam que "ninguém esperaria modelos éticos veiculados nas máximas ditas por personagens diferentes em um mimo. Um contradiria o outro, como provérbios comumente fazem [...] muitos advogariam um pragmatismo egoísta". Evidentemente, o formato épico permite muito mais a Lucano do que o mimo permitiu a Públio.

${ }^{7}$ Morales 2004, 96-151.

${ }^{8}$ Bennington 1985,9 .

${ }^{9}$ Morales 2004, 108.

${ }^{10}$ Bennington 1985, 85: "Sentenciosidade se torna não tanto um 'tipo de sentença' quanto uma força nos textos [...]. Esta força não é uma entidade irracional ou metafísica, supostamente operando nos textos, é sim uma força de lei. Se os tipos mais claros de sentenciosidade fixam a lei, os tipos mais encobertos [...] tiram sua força da lei estabelecida ou aproveitam-se desta lei furtivamente".

${ }^{11}$ Cf. Bennintgton 1985, 62: "O texto na qual sentenciosidade é encontrada se torna um texto disperso em um intertexto em que sentenciosidade é um traço significante, enquanto isso a sentenciosidade propriamente dita é dispersa pelas narrativas". 
narrativa e mantemos somente a ideologia. A performance de Virgílio de uma história sobre Enéas é reduzida à ideologia, se torna puramente ethos; e como resultado somos confrontados com a essência.

Virgílio, então, mostra o caminho para sua audiência se perguntar o que a Eneida transmitiu ao leitor augustano. Consequentemente, o poeta legou a possibilidade de uma crítica pró- e antiaugustana. Ao ler as sententiae virgilianas, negociamos com tal questão, simultaneamente construímos a mensagem do poeta e nos perguntamos o que esse épico significa para nós hoje em dia. Minha leitura "moralizante" suplanta a narrativa em favor de suas sententiae e degrada a épica virgiliana quasi a uma fábula que ilustra uma moral, uma sententia, um epimythion - ou mesmo muitas delas. Assim como a fábula é suplementada por sententiae, "a máxima tende a suplantar a fábula, a substituí-la uma vez que não há mais ficção".12

Mostrarei a seguir como Virgílio tem êxito na construção de um discurso retórico marcado, formando um sistema com suas sententiae, fio-condutor da ideologia de sua épica. Em seguida, proponho uma leitura de Virgílio tendo em vista seu caráter sentencioso/sentenciosidade (sententiousness). As sententiae possuem mais do uma função puramente formal e estrutural e constituem-se como uma importante contribuição para o significado e unidade da Eneida. Funcionam como uma rede que liga os diferentes segmentos da épica, padronizando o texto ao evidenciar distintos argumentos éticos e ao mapear o universo da épica. Sententiae também permitem que Virgílio transcenda a ocasião imediata de seu poema, criando membros em seu corpo textual, dos quais, prontamente, escritores na caça por fórmulas sagazes se apropriaram. Em uma cultura em que a divisão do texto em excertos era algo a ser valorizado, em que a audiência examinaria com cuidado o texto na expectativa de encontrar sententiae adicionáveis às suas coleções pessoais, Virgílio poderia até mesmo antecipar uma versão de seu épico ao longo dos versos dos mimos reciclados de Públio Siro..$^{13}$ Em fama e pós-vida, este contemporâneo de César agora depende somente de uma coleção de sententiae extraídas de suas peças. ${ }^{14}$ Estudados como um manual escolar na Antiguidade e louvados por Sêneca, o Jovem, e Gélio, esta antologia era,

${ }^{12}$ Bennington 1985, 85.

${ }^{13}$ O criticismo dos primeiros discursos de Cícero no Diálogo de Tácito (22.3) incorpora esta ideia: nihil excerpere, nihil referre possis, et velut in rudi aedificio, firmus sane paries et duraturus, sed non satis expolitus et splendens ("Não há nada a extrair, nada que tu possas levar contigo: é apenas como um edifício rude, onde as paredes são fortes, consciente e duradouro, mas deficiente de polimento e lustre").

${ }^{14}$ Cf. Giancotti 1967, 318-38. O comentador sugere várias possíveis origens para esta antologia no século i d.C.: como manual escolar retórico, como método gramatical ou como introdução à ética e política. 
ainda no século xIx, considerada leitura edificante..$^{15}$ Além disso, propõe-se que houve uma coleção de sententiae extraídas dos Anais de Ênio, uma vez que a obra se ofuscara e quase se extinguira com a chegada da Eneida - à qual devemos muitos dos fragmentos dos Anais que chegaram até nós.

Seria, então, as sententiae a la Públio Siro a única estratégia de leitura da obra de Virgílio? Já vimos no começo deste artigo que Virgílio atribui significado às suas sententiae não apenas em seus contextos imediatos. $\mathrm{O}$ que nós, como leitores, ganharíamos se as alinhássemos em uma cadeia de reflexões em série? A seguir, apresento uma seleção de sententiae relacionadas tematicamente, assim, nuanças distintas de sinônimos próximos e ideias paralelas se tornam aparentes. Seremos, então, capazes de seguir o discurso virgiliano de valores e conceitos de seu universo épico.

Primeiro, observarei alguns dos versos obviamente sentenciosos da Eneida organizadas por tema; no momento, observarei somente as gnomai, sententiae de caráter genérico. Um óbvio grupo temático é aquele concernente à lida do amor:

- quid uota furentem,/quid delubra iuuant? (4.65ss, gnome implícita de Dido: "De que adiantam templos e votos a quem delira de amor?");

- quis fallere possit amantem? (4.296, gnome: "Quem poderá enganar um amante?");

- improbe Amor, quid non mortalia pectora cogis! (4.412, epiphonema e gnome implícita: “Ímprobo Amor, que estragos fazes nos peitos dos homens!");

- uarium et mutabile sempre/femina (4.569ss: "A mulher é sempre uma coisa inconstante e mutável").

Dois destes exemplos tomam a forma de perguntas retóricas, que são marcas da voz autoral, assim também é o último exemplo. O terceiro exemplo, endereçado ao Amor, é encontrado ao fim de um discurso desesperado de Dido como epiphonema - um realce retórico no fim de discurso direto. Aristóteles em sua discussão sobre o uso de gnome na Retórica (2.21.1395b) sugere que talvez haja relação entre o caráter moral do autor e a qualidade ética de sua gnome:

[...] aspectos em que o uso das máximas traz vantagens, mas há outros ainda melhores: quando elas conferem aos discursos um caráter "ético". Têm caráter "ético" os discursos que manifestam claramente a intenção do orador. Todas as máximas cumprem esta função, porque exprimem de forma geral as intenções daquele que as enuncia, de tal sorte que, se as máximas são honestas, também farão que o caráter do orador pareça honesto. ${ }^{16}$

${ }^{15}$ Cf. Benz 2001. Knecht (1998, 53-5) destaca que o frequente uso de paronomásia nas sententiae (assim como os provérbios) já as tornava útil como manual de ensino aos iniciantes em latim na Antiguidade.

${ }^{16}$ N.T.: tradução de Júnior, Alberto \& Pena, São Paulo: Martins Fontes, 2012. 
Sendo assim, estamos dispostos a acreditar que Virgílio era um misógino velho e amargo que desprezava tanto as mulheres quanto o amor? Com certeza não, pois esta seria uma leitura biográfica ingênua de nosso material. Entretanto, o que podemos deduzir destes poucos excertos da Eneida é que eles apoiam a visão de que a Eneida não é um texto que endossa uma perspectiva positiva sobre amor e romance (ou até mesmo mulheres).

Outros campos temáticos explorados na Eneida são os do destino inconstante e do valor da virtude. Como estes estão comumente correlacionados, os apresentarei juntos:

- sunt hic etiam sua praemia laudi / sunt lacrimae rerum et mentem mortalia tangunt (1.461-2, gnome: "Aqui, também, a Virtude encontra sua recompensa; aqui, também, há lágrimas por desastres e lamentos tocam o coração");

- at sperate deos memores fandi atque nefandi ( 1.543 , ex contrariis e gnome: "E olha para os deuses que lembram o que é certo e errado");

- degeneres animos timor arguit (4.13, gnome: "O medo revela almas de baixa natureza");

- audentis Fortuna iunat (10.284, final do discurso de Turno, epiphonema e gnome: "A Fortuna ajuda o audacioso");

- stat sua cuique dies, breue et inreparabile tempus / omnibus est uitae; sed famam extendere factis / hoc uirtutis opus (10.467-9, Hércules suplica, Júpiter responde; três gnomes: “Cada um tem seu dia marcado, breve e irreparável é o tempo de vida para todos; mas para prolongar a fama com feitos, este é um trabalho valoroso");

- nescia mens hominum fati sortisque futurae / et saruare modum rebus sublata secundis! (10.510ss; a Turno, depois que roubou o cinturão de Palas: “Ó mente humana, ignorante de seu destino, do que virá e de que como dominar-se");

- multa dies uariique labor mutabilis aeui / rettulit in melius, multos alterna reuisens / lusit et in solido rursus Fortuna locauit. (11.425-7, Turno aceita o desafiar Enéas, gnome: "Muitas vezes um mal foi curado pelo tempo e os trabalhos do dia mudanças inesperadas trazem. A muitos homens, Fortuna, visitante incerta, tem incomodado, para por fim deixá-los em situação estável"); - usque adeone mori miserum est? (12.646, Turno reconhece sua irmã, gnome: “Mísera é a morte?").

A partir destas sententiae, podemos facilmente construir um universo épico em que a virtude é o bem maior, a morte é provável e Fortuna, Destino e os Deuses estão operando. Palavras-chave, tais como mors, labor, Fortuna, fatum, virtus e dei, ocorrem e representam valores-chave do texto; mesmo estes poucos versos já delineiam a moral e o código épico da Eneida. 
Na segunda parte deste artigo, examinarei as sententiae em Lucano, a fim de mostrar como o autor desenvolve e, ocasionalmente, subverte a herança literária oriunda de Virgílio.

\section{$*$}

Os estudos da Guerra Civil de Lucano firmaram a alcunha "épica retórica". Esse rótulo acena a noção de virtuosidade verbal ao mesmo tempo em que alerta os perigos da declamação vã e da falta de substância. Além do mais, assinala o processo de reabilitação de alguns recursos retóricos de Lucano. ${ }^{17}$

Tomando a sentenciosidade (sententiousness) como uma força conservadora, veremos que muitos discursos de Lucano são baseados em elementos tradicionais da cultura romana. Através da sentenciosidade de Lucano, a matéria tradicional é apresentada de modo que a audiência a compreenda.

\section{Queda e apocalipse}

A obsessão de Lucano pela queda e apocalipse de Roma, propositadamente, recorda um jogo etimológico presente na transliteração grega de Roma em 'P $\omega \mu \eta$. A identificação - um tanto quanto lisonjeira - entre 'P $\omega \mu \eta$ e $\dot{\rho} \omega \dot{\mu} \eta$ ("força"), em grego, quase implora por trocadilhos e exploração ideológica. ${ }^{18}$ Entretanto, há um lado mais obscuro onde palavra e som brincam: o terceiro oráculo Sibilino iguala 'P $\omega \mu \eta$ a ṕú (ruína). Ambas as conotações de 'P $\omega \mu \eta$ são capturadas no epodo de Horácio sobre a Guerra Civil (16): suis et ipsa Roma uiribus ruit confirma que os poetas latinos estavam cientes de tais ecos. ${ }^{19}$

Lucano inicia o primeiro verso de seu épico com o mesmo imaginário: a inabilidade de Roma em se manter e o colapso das estruturas de poder se tornam o slogan da campanha deste épico. Por todo o poema, a imagem da queda é evocada, sendo posta em camadas na memória do leitor: Pompeu evoca esta imagem ao se dirigir à Cornélia, enquanto César age mais ativamente. Para completar a cena, Lucano deixa claro que está "descompondo" a Eneida: tanti periere labores. Esta sentença evoca superficialmente a invocação a Musa de Virgílio nos versos iniciais da Eneida: a Musa nos lembrará das incontáveis fadigas - as quais levaram a fundação de Roma - de Enéas.

Além disso, o filho de Pompeu sabe que pode se chamar de "senhor do universo ou herdeiro da vasta extinção". A autodestruição do projeto

${ }_{17}$....magis oratoribus quam poetis imitandus (Inst. Or. 10.1.90). Cf. Morford 1967, 85-8. Nadaï 2000 também analisa Lucano por uma perspectiva retórica, mas advoga uma abordagem revisionista.

${ }_{18}$ Cf. Macleod 1979, 220 ss.

19 "... à sua própria força, Roma se abate" (Hor. Ep. 16.2). Cf. Or. Sib. 3.336 (repetido em 8.165-

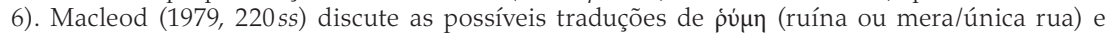
propõe que este exemplo é uma extensão do sentido do significado usual de "ímpeto, impulso". 
romano é realçada por uma reviravolta retórica quando os soldados enfrentam uma batalha autodestrutiva: "Avançamos ao desastre, clamando por guerra, que nos aniquilará". Finalmente, duas gnomai aparecem, soando verdadeiras tanto para Roma quanto a Pompeu: "velhice e vida após o poder destroem espíritos heróicos" é seguida por "a não ser que o dia final coincida com o fim das dádivas, por morte rápida que evita sofrimentos, a antiga fortuna traz desgraça". A imagem de Pompeu levando consigo o mundo em sua derrocada encerra este discurso em ruínas (ele procura uma raça para compartilhar sua queda). Uma última imagem de destruição fecha o discurso: "até mesmo as ruínas caíram no esquecimento".

Quando lidas em sua ordem de surgimento, pouco contextualizadas, e através do olhar de um orador à procura de sententiae, estes exemplos transmitem algo sobre a essência da Guerra Civil. Elas nos permitem vislumbrar o universo de Guerra Civil. Lucano retoma a mesma questão - a queda de Roma - repetidas vezes e de diversas maneiras. Em todo o momento em que a atenção do leitor é redirecionada para este tópico, toda vez que o leitor se depara com isso, Lucano nos pergunta se conseguimos entendê-lo, se conseguimos, através do envolvimento com o universo da guerra civil, pensar algo a mais sobre o assunto.

\section{Fuga}

Em seu epodo sobre a guerra civil, Horácio tenta não tanto encontrar um remédio para a guerra civil e sim uma fuga. O poema é recoberto de ecos acerca de fugas: Horácio deseja que os romanos dirijam-se para a ilha dos bem-aventurados e finaliza o poema com a imagem da secunda fuga. Entretanto, os fócios, aos quais Horácio menciona como um povo que escapou do exílio - uma fuga de sucesso - terminaram pegos novamente em uma história de guerra. Depois de viajar ao oeste, eles encontraram Massilia, uma cidade da qual a derrota pelas tropas de César é apresentada no livro III da Guerra Civil. Ademais, a tradição épica nos lega exemplos proeminentes de fugitivos de guerra; o próprio Enéas é introduzido na Eneida como fato profugus. ${ }^{20}$ Nos voltaremos para a fundação de Roma. A fuga de Enéas provê o início de outra narrativa e vincula uma experiência humana recorrente: após a fuga, haverá uma reforma da comunidade. ${ }^{21}$ Em contraste, a jornada

20 "...exilado pelo destino" (Verg. A. 1.2). Austin (1971, ad loc.) coloca que profugus é usualmente atribuído a Enéas e à migração troiana. O comentador fornece uma série de exemplos.

${ }^{21}$ Lucano também incorpora histórias de fundação (ctisticas). Ele nos conta que Brundisio foi fundada por dicteanos (do monte Dicte) que eram fugitivos de Creta (2.610-12). Além disso, também encontramos Celtas, fugitivos oriundos de raça antiga de gauleses, que se dizia terem emergido dos ibéricos (4.9ss). 
épica de Lucano inverte o projeto de Enéas: não escaparemos para a fundação de Roma, mas sim da fundação de Roma. No universo da guerra civil, Lucano completa a lógica de se fugir, invertendo a fuga. Diferentemente da Eneida, desta vez não haverá como fugir, o leitor é constantemente bombardeado com sententiae, enquanto que o processo de racionalização da fuga se prepara para ser um obstáculo constante.

A primeira sententia nutrida por este discurso deixa clara a direção em que o épico está se movendo: não construtivamente para Roma, mas destrutivamente contra ela, tanto fisicamente quanto ideologicamente: sic urbe relicta / in bellum fugitur ("assim desertando a cidade, eles escapam para a guerra", 1.503-4). Ademais, Lucano se deleita em subverter e dizer os fatos diretamente. Aqueles que fogem para a guerra são tratados com respeito: civis, qui fugerit, esto ("Que seja considerado cidadão aquele que foge", 7.319). No entanto, aqueles que vencem são colocados para correr: victore fugato ("o vencedor é afugentado", 7.824). Além disso, o que Magno chama de fuga, outro chama de triunfo: heu demens, non te fugiunt, me cuncta secuntur ("Ó Demente! Não é de ti que eles escapam, mas a mim que eles seguem", 2.275). Entretanto, há mais no que se pensar: Lucano também coloca em exercício uma "perversa etiqueta customizada" no tocante à matança no campo de batalha. $\mathrm{O}$ conceito de morte honrosa em ação se perde quando aqueles que fogem são mortos como se estivessem lutando heroicamente: excipiant recto fugientes pectore ferrum ("enquanto fogem, deixa que recebam no peito as armas", 4.166). Além do mais, a tradicional "quem foge de quem" da narrativa convencional é constantemente posta à prova e problematizada. Não os vivos, mas os mortos escapam da morte, todas as tropas de Pompeu escapam de um único homem e a guerra escapa de César ("cadáveres escaparam da morte", 6.532; "Tu somente, Sceva, fugiu de todos esquadrões", 6.249; bellum te civile fugit, "a guerra civil foge de ti", 5.316).

Ainda, aqueles marcados como desertores não são aqueles aos quais nomearíamos como tais, i.e. Cornélia; fida comes Magni vadit duce sola relicto/ Pompeiumque fugit ("leal companheira de Magno, ela vai só, abandonando o general e correndo de Pompeu", 5.804-5). O livro Ix apresenta, em particular, muitos exemplos de tentativas de reconciliação pela fuga da batalha de Fársalo. Aqui, as sententiae comunicam-se entre si e desenvolvem o mesmo esquema de reflexões por toda a sequência. Desde o início do livro em diante, a marcha pelo deserto é construída como uma aristeia; assim, os soldados fugitivos podem recuperar a honra perdida. Consequentemente, a aparição deles é vista como a de uma frota vitoriosa: "Quem pensaria que em tantos navios as tropas escaparam? Ou que o mar para navios conquistados seria tão estreito?" (9.34-5). Em sua censura, Catão deixa claro que o que virá é mais do 
que uma simples fuga. ${ }^{22}$ De fato, o deserto da Líbia é um grande desafio, um trauma muito pior do que a batalha de Fársalo: sola potest Libye turba praestare malorum / ut deceat fugisse viros ("Somente Líbia com sua turba de males pode mostrar aos guerreiros que convinha ter fugido", 9.405-6). Então, os soldados de Catão desejam retornar à Tessália, ansiando que as tropas de César os persigam, pois assim, estes soldados também sofreriam das mesmas privações: reddite, di, clamant miseris quae fugimus arma, / reddite Thessaliam ("Eles clamam: 'Deuses, devolvei em nossa miséria a batalha da qual fugimos, devolvei a Tessália"', 9.848-9); solacio fati / haec petimus: veniant hostes, Caesar que sequatur / qua fugimus ("Pedimos este prazer no nosso destino: que venham os inimigos, que César nos siga até onde nós fugirmos", 9.879-81).

Entretanto, podemos também interpretar esses desafios como punições pela fuga: assim como a Líbia é a pena dos soldados, Ptolomeu é a pena de Pompeu (poena fugae Ptolomaeus erat, "a pena da fuga era Ptolomeu", 9.1087). Por fim, o poema se encerra onde a fuga termina; não há escapatória da guerra civil via nulla salutis, / non fuga, non uirtus: vix spes quoque mortis honestae ("Não há caminho da salvação, nem fuga, nem heroísmo: há também pouca esperança de uma morte honrosa", 10.538-9).

Ao fim deste breve panorama da sentenciosidade de Lucano, alcançamos uma leitura de suas formulações mais sagazes, insistindo na importância que elas têm como parte de um discurso maior sobre temas-chave da épica. As sententiae de Lucano, longe de ser apenas estuque retórico, ditam as leis, circunscrevendo a ética da guerra civil. Não há modo melhor de se mostrar a força destes versos do que indicar o conjunto de sententiae que organizam o discurso de Potino. Aqui o poeta está exultante em retórica, mas também está determinado em deixar claro quais e de quem são as normas que governam o Egito. A passagem como um todo encapsula o projeto sentencioso de Lucano de estabelecer a lei em poucos versos:

- 8.484 ius et fas multos faciunt, Ptolomae, nocentes ("Lei e justiça, Ptolomeu, transformam muitos em culpados");

- 8.485-6 "dat poenas laudata fides, cum sustinet" inquit / "quos fortuna premit" ("Lealdade, embora louvada, cumpre a pena ao suportar o povo que a Fortuna esmaga");

- 8.486-7 fatis accede deisque, / et cole felices, miseros fuge ("Fica do lado do Destino e dos Deuses, cultiva os felizes, foge dos infelizes");

- 8.487-8 sidera terra / ut distant et flamma mari, sic utile recto ("Assim como as estrelas distam da terra e o fogo do mar, assim também o útil dista do que é certo");

${ }^{22}$ Cf. ... ignavum scelus est tantum fuga ("o crime de um covarde é a mera fuga", 9.283). 
- 8.489-90 sceptrorum vis tota perit, si pendere iusta / incipit ("Todo o poder de cetros desaparece se isto começa a pesar a justiça");

- 8.490 euertitque arces respectus honesti ("A apreciação do que é honrável destrói cidadelas");

- 8.490-1 libertas scelerum est quae regna inuisa tuetur / sublatusque modus gladiis ("a liberdade de cometer crimes é o que protege os reinos odiosos, e a ausência de limite à espada");

- 8.491-2 facere omnia saeve / non inpune licet, nisi cum facis ("Tu não podes agir brutalmente sem ser penalizado, a não ser quando o faças");

- 8.492-3 exeat aula / qui volt esse pius ("que aquele que deseja ser bom abandone a contenda");

- 8.493-4 virtus et summa potestas / non coeunt ("A virtude e o sumo poder não são compatíveis");

- 8.494-5 semper metuet quem saeva pudebunt ("Aquele que tem vergonha da crueldade sempre terá medo").

Potino emprega sententiae no início de seu discurso para indicar autoridade, de movo a fazer com que o jovem rei Ptolomeu siga sua sugestão de matar Pompeu. Todos estes posicionamentos soam verdadeiros à sua maneira e não precisam de demasiadas justificativas. Sendo assim, Potino projeta a reação desejada a seu plano, uma estratégia que tem êxito. Todos os conselheiros concordam com o crime e o jovem rei comanda o assassinato. Além disso, tais sententiae também servem para caracterizar Potino - a palavra é o homem - e ilustram a ética vigente na corte egípcia, se não toda a guerra civil em um grão de arroz. Por fim, como exemplificado anteriormente pelas sententiae de Virgílio, esta ferramenta estilística emerge - através deste estudo breve e em curso - como um importante significativo elemento da tradição épica latina. ${ }^{23}$

\section{REFERÊNCIAS}

Austin, R. G. 1971. Aeneidos liber primus. Oxford: Clarendon Press.

Bennington, Geoffrey. 1985. Sententiousness $\mathcal{E}$ the Novel: laying down the law in eighteenth-century French fiction. Cambridge Studies in French. Cambridge: Cambridge University Press.

\footnotetext{
${ }^{23} \mathrm{O}$ autor deseja agradecer Bárbara Costa pela tradução ao português.

Email do autor: martin.dinter@kcl.ac.uk

Tradução: Bárbara Costa
} 
Benz, Lore. 2001. "Publilius Syrus." In Der Neue Pauly, eds. Hubert Cancik and Helmuth Schneider, 582. Stuttgart: Metzler.

Fantham, Elaine. 2004. The Roman World of Cicero's De Oratore. Oxford: Oxford University Press.

Fantham, Elaine, and J.W. Duff. 1996. "Publilius Syrus." In The Oxford Classical Dictionary, eds. Simon Hornblower and Antony Spawforth, 1276. Oxford: Oxford University Press.

Giancotti, Francesco. 1967. Mimo e gnome, studio su Decimo Laberio e Publilio Siro. Biblioteca di cultura contemporanea, vol. 98. Messina, Firenze: Casa editrice G. D'Anna.

Keith, A.M. 2000. Engendering Rome: women in Latin epic. Roman literature and its contexts. Cambridge: Cambridge University Press.

Knecht, Theodor. 1986. "Das römische Sprichwort - Abgrenzungen, Formen, Anwendung." In Reflexionen antiker Kulturen, ed. Peter Neukam, 47-59. München: Bayrischer Schulbuch-Verlag.

Macleod, Colin. 1979. "Horace and the Sibyl (Epode 16.2)." CQ 29: 220-1.

Mcgill, Scott. 2005. Virgil Recomposed, The Mythological and Secular Centos in Antiquity. Oxford: Oxford University Press.

Morales, Helen. 2004. Vision and Narrative in Achilles Tatius' Leucippe and Clitophon. Cambridge Classical Studies. Cambridge: Cambridge University Press.

Morford, Mark P. O. 1967. The poet Lucan: studies in rhetorical epic. Oxford: Blackwell.

Narducci, E. 2002. Lucano: un'epica contro l'impero; interpretazione della Pharsalia. Roma: Laterza.

Rieks, Rudolf. 1978. "Mimus und Atellane." In Das römische Drama, ed. Eckard Lefèvre, 348-377. Darmstadt: Wissenschaftliche Buchgesellschaft.

Sanford, E.M. 1934. "Quotations from Lucan in Medieval Latin Authors." AJPh 55: 1-19.

Sinclair, Patrick. 1995. Tacitus the sententious historian: a sociology of rhetoric in Annales 1-6. University Park, Penn.: Pennsylvania State University Press.

\section{$*$}

Abstract. This paper examines Virgil's and Lucan's sententiae, a much-neglected rhetorical feature of Latin epic. While Virgil's sententiae are frequently quoted by later authors, Lucan in particular was famous for his highly rhetorical sententiae in antiquity (cf. Quint. Inst. 10.1.90). Lucan strives on the syntactic level to create unique and memorable phrases, which secure the Nachleben of his epic body through excerptability. Reading of Lucan as a mine for one-liners is no modern imposition, but instead confirms that this style of reading brings out the strength of the poem's energetic formulation of its key themes such as downfall and flight: sententiae lay down the epic's laws and simultaneously create a discourse on epic values that spans the entire epic.

Keywords. Sententiae, Latin epic, Virgil, Lucan, fuga, apocalypse. 